\title{
Controle Postural e Desenvolvimento Motor em Crianças com Paralisia Cerebral Luciana Maria dos Reis
}

Docente em Fisioterapia Neurofuncional, Universidade Federal de Alfenas - UNIFAL, Alfenas-MG, Brasil.

O termo paralisia cerebral (PC) refere-se a um grupo de desordens posturais e de movimentos decorrente de uma lesão cerebral não progressiva e permanente que ocorre durante o desenvolvimento de um cérebro imaturo, gerando alterações de tônus, movimento e controle postural $^{1}$.

O controle postural está relacionado à habilidade de manter o centro de gravidade sobre uma base de suporte, sendo fundamental no desenvolvimento motor. Crianças com PC apresentam menor equilíbrio postural pelo comprometimento de funções motoras e sensoriais, alteraçóes no tônus, deformidades articulares, encurtamento e desequilíbrio muscular, com consequente prejuízo no desenvolvimento motor e maior dependência nas atividades de vida diária (AVDs) ${ }^{2,3}$.

As alteraçóes motoras, principalmente as relacionadas ao controle postural, observadas na PC, levam a um importante diferencial em relação a crianças com desenvolvimento motor típico, necessitando melhor direcionamento no tratamento e orientaçóes para familiares e cuidadores por parte de profissionais voltados para a reabilitação ${ }^{4}$.

Este diferencial foi descrito no estudo "Controle Postural em Crianças com Paralisia Cerebral e Desenvolvimento Típico ${ }^{5}$, realizado com 64 crianças divididas em quatro grupos, sendo: G1: cinco e seis anos; G2: sete e oito anos; G3: nove e dez anos, com desenvolvimento típico, e; G4: cinco a 12 anos, com PC.

Foi observado, por meio da Escala de Equilíbrio Pediátrica, Teste de Alcance e Plataforma de Força, que a criança com PC tem prejuízo no controle postural, na realização de atividades funcionais, na mobilidade e área do centro de pressão, tendo o seu desempenho próximo ao de crianças com desenvolvimento típico na faixa etária entre cinco e seis anos.

Observou-se ainda que o grupo com PC tem menor amplitude de movimento de ombro, que é contra- balanceado com movimentos compensatórios de tronco, desafiando ainda mais o equilíbrio, uma vez que o centro de gravidade é retirado da base de suporte. A presença de contratura e espasticidade também é descrita como responsável pela restrição dos movimentos, interferindo nas resposta de controle postural.

Em relação ao processo de maturação, foi observado que a medida que a idade aumenta ocorre melhora do desempenho de controle postural nas crianças em desenvolvimento típico, tanto em testes funcionais, quanto nos parâmetros estabilográficos.

Diante dos resultados observados, os autores relatam as alterações no repertório motor e a diminuição do número de estratégias e habilidades como possivelmente relacionadas à diminuição da performance do controle postural em crianças com PC e ressaltam a importância da ênfase, na prática clinica, no desenvolvimento do controle postural, seja utilizando métodos convencionais ou por meio de outras abordagens, além da melhor manutenção na posição unipodal, sendo necessário o treinamento de transferência de peso e também de controle seletivo do membro afetado, quando em apoio contralateral.

Estudos como este são de grande relevância uma vez que colaboram fortemente para a melhor compreensão do desenvolvimento de crianças com PC, bem como seu diferencial em relação ao desenvolvimento motor típico, favorecendo um melhor desempenho na prática clínica, bem como a elaboração de novas pesquisas direcionadas para a melhoria das estratégias e métodos de tratamento cada vez mais específicos para esta condição clínica.

\section{REFERÊNCIAS}

1.Lopes, GHR, David AC. Posturografia na análise do equilíbrio em crianças com paralisia cerebral: revisão de literatura. Fisioter Pesq 2013;20:97-102. http://dx.doi.org/10.1590/S1980-65742011000400009

2.Grecco LAC, Tomita SM, Christovão TCL, Pasini H, Sampaio LMM, Oli- 
veira CS. Effect of treadmill gait training on static and functional balance in children with cerebral palsy: a randomized controlled Trial. Braz J Phys Ther 2013;17:17-23. http://dx.doi.org/10.1590/S1413-35552012005000066

3.Pavão SL, Nunes GS, Santos AN, Rocha NACF. Relationship between static postural control and the level of functional abilities in children with cerebral palsy. Braz J Phys Ther 2014;18:300-7. http://dx.doi.org/10.1590/bjpt-rbf.2014.0056
4.Cesa CC, Alves MES, Meireles LCF, Fante F, Manacero SA. Avaliação da capacidade funcional de crianças com paralisia cerebral. Rev CEFAC 2014;16:1266-72. http://dx.doi.org/10.1590/1982-021620146513

5.Vitor LGV, Silva-Junior RA, Ries LGK, Fujisawa DS. Controle postural em crianças com paralisia cerebral e desenvolvimento típico. Rev Neurocienc 2015;23:41-7. http://dx.doi.org/10.1590/1982-021620146513 